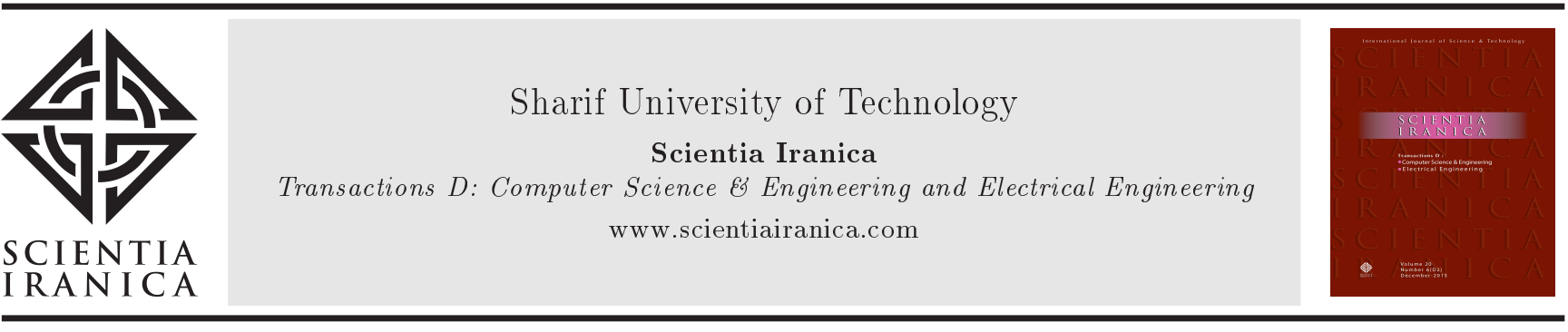

\title{
Optimum pole arc offset in permanent magnet synchronous generators for obtaining lowest voltage harmonics
}

\author{
A. Dalcali ${ }^{a *}$ and M. Akbaba ${ }^{\text {b }}$ \\ a. Department of Electrical-Electronics Engineering, Karabük University, 78050, Karabük, Turkey. \\ b. Department of Computer Engineering, Karabük University, 78050, Karabük, Turkey. \\ Received 22 December 2015; received in revised form 13 June 2016; accepted 19 July 2016
}

\author{
KEYWORDS \\ Synchronous \\ generator; \\ Pole arc offset; \\ Surface mounted; \\ Voltage wave-shape; \\ THD.
}

\begin{abstract}
In this study, the effect of parametric variation of pole arc offset distance on the performance of a Permanent-Magnet Synchronous Generator (PMSG) used in wind energy applications has been investigated. Fourier analyses of the voltage wave-shapes that are obtained by the parametric variation of the pole arc offset value have been made. The THD is determined for each voltage wave-shape. As a result of optimization study, the efficiency and output power have been kept approximately constant. The THD of the output voltage has decreased.
\end{abstract}

(C) 2017 Sharif University of Technology. All rights reserved.

\section{Introduction}

Significant advancement in environmental awareness and rapid decrease in fossil-fuel sources have resulted in the increased use of cheap and environmentallyfriendly renewable energy sources [1-3]. Among the renewable energy sources, wind energy takes a vital role in decreasing foreign dependence on energy, improving energy reliability, and solving some of the environmental problems. As such, the use of this component of renewable energy is rapidly increasing as the years pass by [4-9]. Different types of electrical generators used with wind turbines have some advantages and disadvantages over one another. Among them, the use of PMSG is rising rapidly in parallel to the developments in Permanent Magnet (PM) technology [3,10-14].

\footnotetext{
* Corresponding author. Tel.: +90 3704332021 ;

Fax: +903704333290

E-mail addresses: ademdalcali@karabuk.edu.tr (A. Dalcali)
}

doi: $10.24200 /$ sci. 2017.4357
In synchronous generators, mainly due to the magnetic saturation and spatial configuration of the pole face, the resultant air-gap flux density is not sinusoidal. As a result, the induced voltage is also not sinusoidal [15]. This issue has many disadvantages such as deteriorating the generator performance, causing some undesired effects on customer equipment, and high circulating currents between generators and infinite bus [16,17].

Wang et al. [18], using FEM and analytic techniques, investigated the effect of pole arc to pole pitch ratio on the third harmonic of the back emf of the $\mathrm{PM}$ brushless DC motors. It has been proposed that at lowvalue pole arc to pole pitch ratio, the third harmonic of the back emf remains at the negligible level. However, this adversely affects the voltage THD, which means an increase in the harmonics of other orders, and motor performance. In [19], the effect of magnet shape and dimensions of disc type axial flux machines on the voltage distortion has been investigated. It is proposed that the voltage THD be minimum in the case of circular type magnets. It is also claimed that the 
voltage THD is decreasing as the magnet thickness increases. In [20], it is shown that the no-load voltage THD of PM generators used with wind turbines is varying with the slot width and magnet pitch. Kim et al. [21] attempted to optimize the THD of PM generators by parametric variation of the number of poles, slot opening, ratio of pole angle, and pole size. It is pointed out that the pole angle and slot opening can be adjusted in such a way as to avoid 3rd voltage harmonic.

In this study, using FE analysis, design of a $2.5 \mathrm{~kW}$ surface-mounted PMSG suitable for use with wind turbines has been realized. Having completed the design phase, using parametric study approach, the pole arc-offset is varied between 0 to $45 \mathrm{~mm}$. The shapes of the phase voltage and air-gap flux density distribution corresponding to each value of the pole arc offset value have been obtained. At the rated load, the Fourier coefficients of the voltage wave-shapes have been determined. These are used to obtain THD $\%$ of the output voltage. In order to keep the output power approximately constant while varying the pole arc offset, the pole-embrace value has been also changed accordingly. In this investigation, electrical energy generation from small-scale wind turbines is targeted. Therefore, it is necessary to select a lowpower and low-speed generators with large number of poles. Accordingly, a surface-mounted inner runnertype PMSG generator has been selected which features 1 poled, $2.5 \mathrm{~kW}, 120 \mathrm{~V}, 84$ slots.

\section{Design of PM synchronous generator}

Design of PMSG starts with the following output Eq. (1):

$$
S=11 \cdot K_{\mathrm{w} 1} \bar{B} \cdot a c \cdot\left(\frac{D}{1000}\right)^{2} \cdot \frac{L}{1000} \cdot n,
$$

where $S$ is the generator's apparent power in VA, $B$ is specific magnetic loading in $\mathrm{T}\left(\mathrm{Wb} / \mathrm{m}^{2}\right), D$ is the stator outer diameter in $\mathrm{mm}, L$ is the stack length in $\mathrm{mm}, K_{\mathrm{w} 1}$ is the stator winding factor, $n$ is the rotor speed in $\mathrm{rpm}, a c$ is the specific electric loading in ampere-turns per meter $(\mathrm{At} / \mathrm{m})$; ac parameter mainly depends on the rated power, frequency, and voltage as expressed in Eq. (2):

$$
a c=\frac{\left(\delta a_{z}\right) Z}{\pi D} .
$$

Phase voltages of a PMSG are expressed as given in Eq. (3) [15,22-24]:

$$
\begin{aligned}
{\left[\begin{array}{l}
v_{a} \\
v_{b} \\
v_{c}
\end{array}\right] } & =\left[\begin{array}{ccc}
R_{a} & 0 & 0 \\
0 & R_{b} & 0 \\
0 & 0 & R_{c}
\end{array}\right]\left[\begin{array}{c}
i_{a} \\
i_{b} \\
i_{c}
\end{array}\right] \\
+ & {\left[\begin{array}{ccc}
L_{a a} & L_{a b} & L_{c a} \\
L_{a b} & L_{b b} & L_{b c} \\
L_{c a} & L_{b c} & L_{c c}
\end{array}\right] \frac{d}{d t}\left[\begin{array}{c}
i_{a} \\
i_{b} \\
i_{c}
\end{array}\right]+\left[\begin{array}{c}
e_{a} \\
e_{b} \\
e_{c}
\end{array}\right](3) }
\end{aligned}
$$

In terms of magnetic flux-linkages $\Psi_{a}, \Psi_{b}$, and $\Psi_{c}$, the voltage equation given in $\mathrm{Eq}$. (3) can be re-written in the form of Eq. (4) as follows:

$$
\left[\begin{array}{l}
v_{a} \\
v_{b} \\
v_{c}
\end{array}\right]\left[\begin{array}{ccc}
R_{a} & 0 & 0 \\
0 & R_{b} & 0 \\
0 & 0 & R_{c}
\end{array}\right]\left[\begin{array}{l}
i_{a} \\
i_{b} \\
i_{c}
\end{array}\right]+\frac{d}{d t}\left[\begin{array}{l}
\Psi_{a} \\
\Psi_{b} \\
\Psi_{c}
\end{array}\right]
$$

The remaining mathematical model of the PMSG, not present in this paper, can be found in detail in $[24,25]$. The generator design parameters are summarized in Table 1.

Figure 1 shows a 3D image of the initial design of a surface-mounted and inner runner configuration

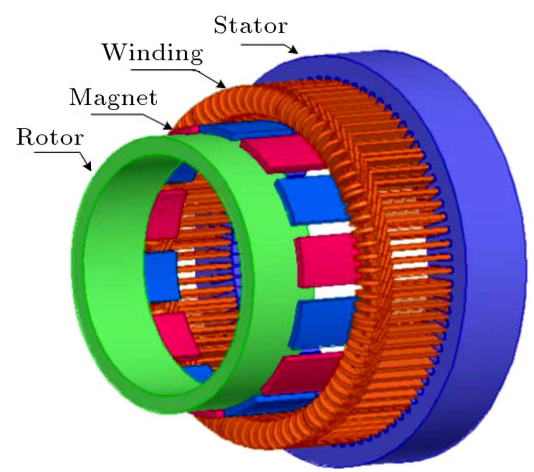

(a)

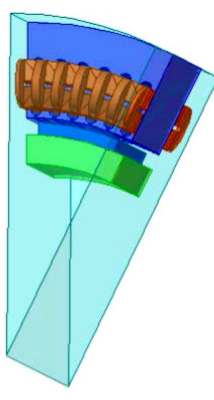

(b)
Figure 1. 3D model of PMSG: (a) Complete view of the PMSG and (b) part section.

Table 1. Main data of the generator under study.

\begin{tabular}{lclc}
\hline Parameters & Values & Parameters & Values \\
\hline Rated power $(\mathrm{kW})$ & 2.5 & Stator outer diameter $(\mathrm{mm})$ & 280 \\
Rated speed $(\mathrm{rpm})$ & 428.5 & Air gap $(\mathrm{mm})$ & 0.8 \\
Rated voltage $(\mathrm{V})$ & 120 & Length of stator $(\mathrm{mm})$ & 54 \\
Permanent magnet & N35 & Pole number & 14 \\
Stator-rotor material & M470 & Number of slots & 84 \\
\hline
\end{tabular}


PMSG. Figure 1(b) shows the 1/14 part section of the full model used in FEM, which is obtained with the aid of master-slave boundary conditions.

\section{Effects of pole arc offset value on the generator design}

The pole arc offset can be determined as the distance of the center of the pole arc to the center of the rotor. The pole embrace is defined as the ratio of $\theta_{1}$ over $\theta_{2}$. $\theta_{2}$ is the mechanical angle corresponding to one pole pitch and $\theta_{1}$ is the angle of one real pole covering one-pole magnet $[26,27]$. According to the numerically calculated machine design procedure, initial pole arc offset value is defined. Then, the solution range and step size of the pole arc offset are defined. The offset point of the synchronous generator pole arc is initially selected as $0 \mathrm{~mm}$ and it is varied up to a maximum value of $45 \mathrm{~mm}$. Figure 2 shows the change in the size of the PM offset points variation. As the offset point value increases, the eccentricity of the tips of PM increases. This leads to a drop in the volume of the PM. As shown in Figure 2, the maximum value of pole arc centre is " $45 \mathrm{~mm}$ ". This is the limit value and no more offset can be assigned to the defined pole number and outer diameter. At each value of the pole arc, the cogging torque, output power, efficiency, induced torque, and load line voltage are investigated.

In order to obtain the generator's rated output power and rated voltage, the total ampere-turn value of the field winding is required. It is determined by the combined contributions of ampere-turn of the stator body, stator teeth air gap, pole face, pole body, and rotor center. All of these parts of the generator from the magnetic circuit reluctance, except for the air-gap reluctance, are all non-linear circuit elements $[15,16]$. At nominal load, the air-gap flux density waveforms of the generator are given in Figure 3 against the varying pole arc offset values.

More sinusoidal air-gap flux density distributions can be obtained by changing the pole arc offset. The nearest sine waveform was achieved when the offset value was set to $45 \mathrm{~mm}$ in the analysis. The resulting waveforms can be expressed as Fourier series given in

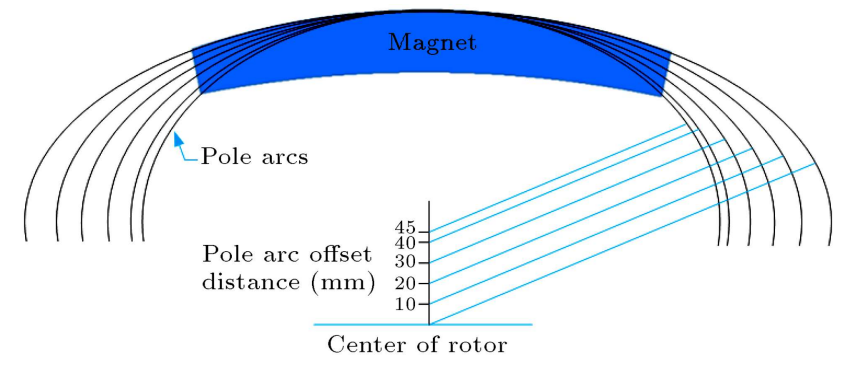

Figure 2. Variation of the parameters of pole arc offset.
Eq. (5) [28]:

$$
B_{\mathrm{g}}(\theta)=A_{0}+\sum_{n=1}^{\infty}\left(A_{n} \cos n \theta+B_{n} \sin n \theta\right)
$$

where $B_{\mathrm{g}}$ is the radial air-gap flux density, $\theta$ is the space angle in electrical degrees, $n$ is the harmonic number, and $A_{n}$ and $B_{n}$ are Fourier coefficients.

The waveform of the voltage induced in the generator windings is a function of the magnetic flux density waveform at the air gap [29]. Therefore, a distorted flux density distribution will lead to a distorted terminal voltage waveform. The simulated induced voltage waveforms at the rated load corresponding to the varying values of the pole arc offset are illustrated in Figure 4. Similar to the air-gap flux density waveform, the best voltage waveform close to a sine wave, is obtained for an offset value of $45 \mathrm{~mm}$.

The magnetic flux density distribution corresponding to $40 \mathrm{~mm}$ pole arc offset value is given in Figure 5. It is obtained by using master-slave boundary conditions. Careful observation of this figure reveals that the flux density distribution is convenient as far as the saturation of the used steel-sheets is concerned.

The variation of the efficiency and power of the generator, which is designed for varying pole arc offset values, is shown in Figure 6. It is already mentioned above that it is desired to keep the output power almost constant. To achieve this while varying the pole arc offset value, the pole-embrace value is also varied accordingly. In this process, it is observed that the efficiency of the generator also remains almost constant.

\section{Total harmonic distortions value of the induced voltage}

In power systems, uninterruptable and high-quality power is always highly demanded. Therefore, for reliable operation of the power systems, it is important to perform the Fourier analysis of the voltage waveform and investigate the harmonics content. The most common way of performing this analysis is to sample the voltage waveform, and then find the average value of each sample [30]. Then, the Fourier coefficients are obtained as given in Eqs. (6) and (7).

$$
A_{n}=\frac{2}{m} \sum_{k=1}^{m}\left(y_{k} \times \sin \left(n \times \theta_{k}\right)\right)
$$

and

$$
B_{n}=\frac{2}{m} \sum_{k=1}^{m}\left(y_{k} \times \cos \left(n \times \theta_{k}\right)\right) .
$$

In the above equations, $m$ is the number of samples in one period of the voltage waveform, $\theta_{k}$, 

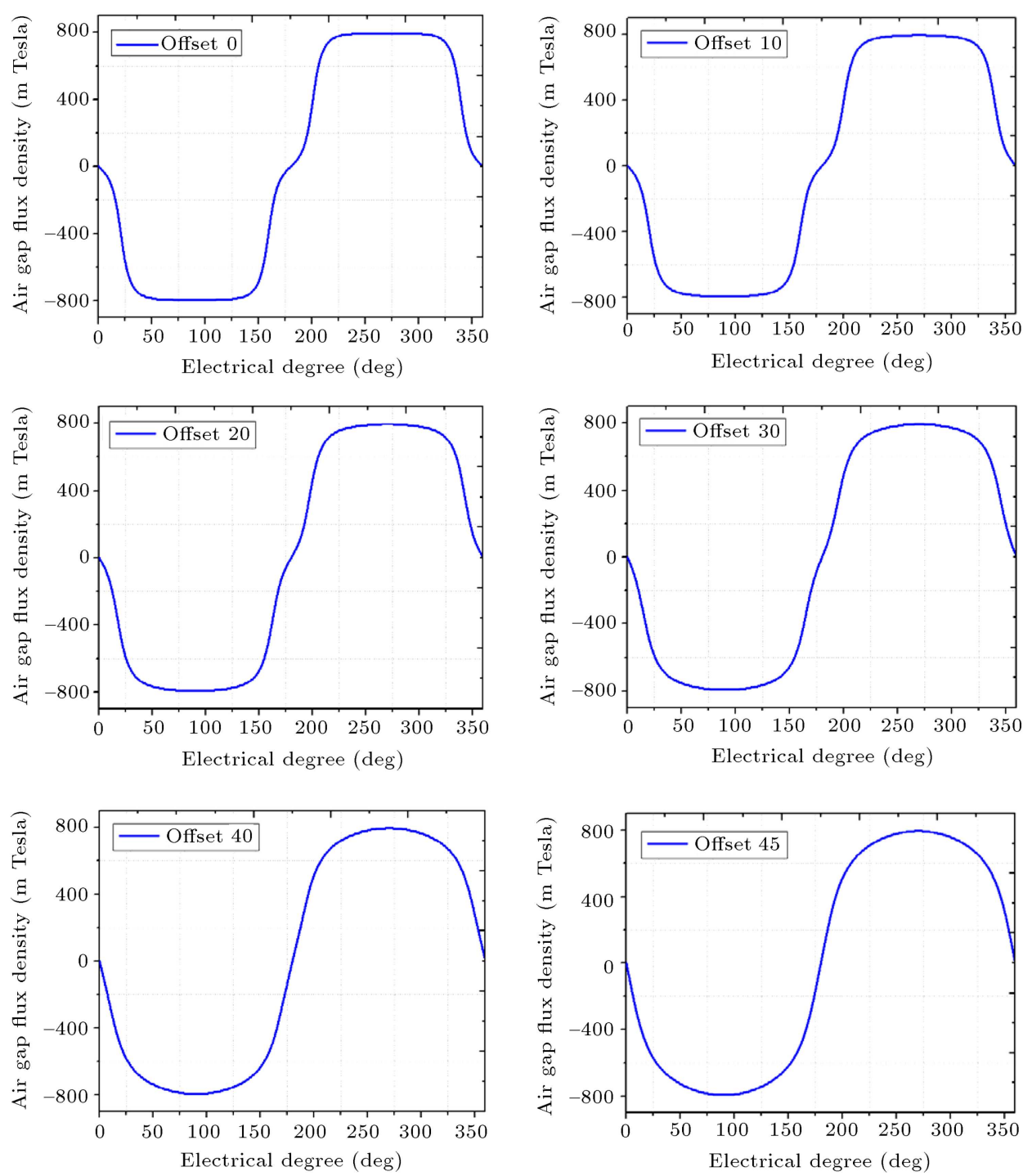

Figure 3. Air-gap flux density spatial distribution.

is the center-point angle of each sample, $(k=$ $1,2, \ldots, m), y_{k}$ is the average value of each voltage waveform sample corresponding to $\theta_{k}$, and $n$ is the harmonic order. Having obtained the Fourier coefficients, the voltage waveform can be expressed as given in Eq. (8) [30]:

$$
\begin{aligned}
V(\theta)= & \sqrt{A_{1}^{2}+B_{1}^{2}} \cdot \sin \left[\theta+\tan ^{-1}\left(\frac{B_{1}}{A_{1}}\right)\right] \\
& +\cdots+\sqrt{A_{n}^{2}+B_{n}^{2}} \cdot \sin \left[\theta+\tan ^{-1}\left(\frac{B_{n}}{A_{n}}\right)\right]_{(8)}
\end{aligned}
$$

The variations of the amplitude and phase angle of the harmonics corresponding to the various pole arc offset values are given in Table 2 .

Knowing that the total voltage is composed of fundamental component and the harmonics, then it can be re-written in the form of Eq. (9) [31]:

$$
V_{s}(t)=V_{s 1}(t)+\sum_{h=1} V_{s h}(t) .
$$

Here, $V_{s}(t)$ is the phase voltage, $V_{\mathrm{s} 1}(t)$ is the fundamental component, and $V_{s h}(t)$ is the harmonic voltage component at $f_{h}$ harmonic frequency. The total distortion in voltage waveform $V_{\text {dis }}(t)$ can be expressed as given in Eq. (10) and it is measured via the concept of percent total harmonic distortion factor (THD\%), which is expressed as in Eq. (11):

$$
\begin{aligned}
& V_{\text {dis }}(t)=V_{s}(t)-V_{s 1}(t) \sum_{h=1} V_{s h}(t), \\
& \% \text { THD }=100 \times \frac{V_{\text {dis }}}{V_{s 1}} .
\end{aligned}
$$

The variation of the voltage THD of the voltage 

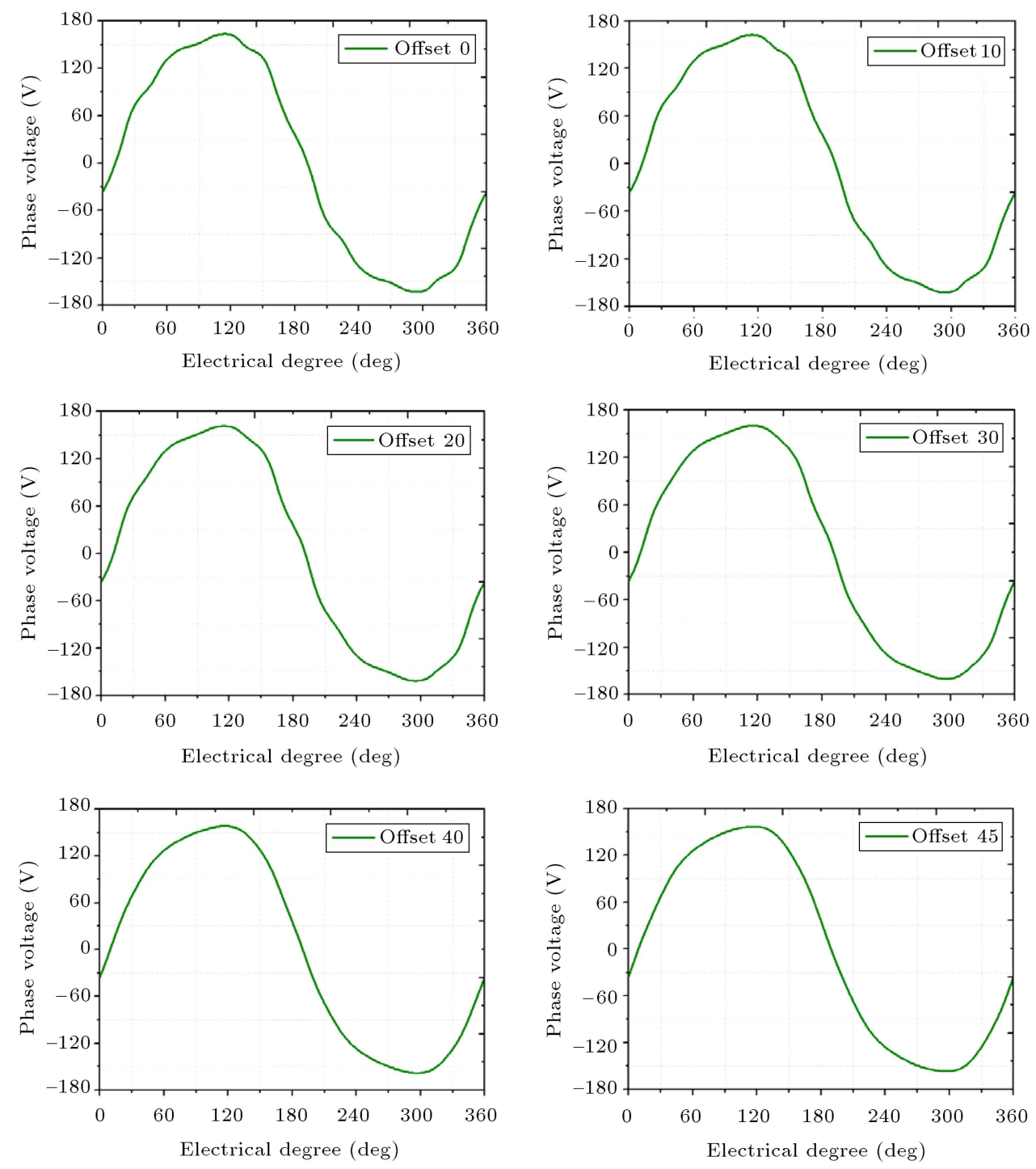

Figure 4. Phase voltage waveforms.

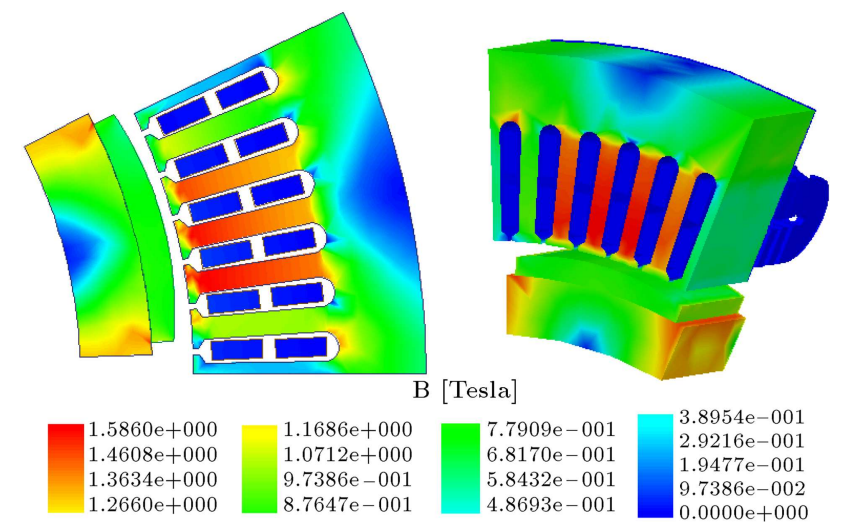

Figure 5. Magnetic flux density distribution $(2 \mathrm{D}$ and 3D).

waveforms given in Figure 3 against the variation of the pole arc offset and embrace values, obtained through Maxwell analysis at the rated load, is given in Table 3 . As a result of the Fourier analysis, it is observed that

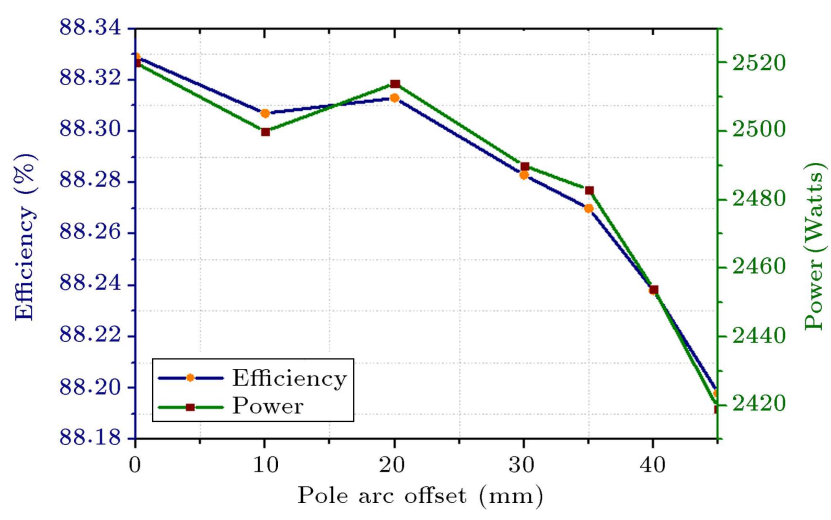

Figure 6. Efficiency and power versus offset changes.

a pole arc offset value of $40 \mathrm{~mm}$ appears to be the optimum value. For this value of the pole arc offset, the following performance values are obtained: generator output power of $2454 \mathrm{~W}$, efficiency of $88.24 \%$, and THD\% of 0.52 . 
Table 2. Variation of the gain and phase angles of the voltage harmonics against the pole arc offset values.

\begin{tabular}{|c|c|c|c|}
\hline $\begin{array}{c}\text { Pole arc } \\
\text { offset }(\mathrm{mm})\end{array}$ & $\begin{array}{l}\text { The degree of } \\
\text { harmonic } \\
\text { components }(n)\end{array}$ & $\begin{array}{c}\text { Amplitude of the } \\
\text { fundamental and } \\
\text { harmonic voltages }(\mathrm{V})\end{array}$ & $\begin{array}{l}\text { Phase angle of the } \\
\text { fundamental and } \\
\text { harmonic voltages } \\
\text { (degrees) }\end{array}$ \\
\hline \multirow{4}{*}{0} & 1 (fundamental) & 170.86 & -11.63 \\
\hline & 5 & 0.323 & 19.76 \\
\hline & 7 & 0.620 & 19.77 \\
\hline & 11 & 2.523 & 3.512 \\
\hline \multirow{4}{*}{10} & 1 & 170.207 & -11.64 \\
\hline & 5 & 0.252 & 32.15 \\
\hline & 7 & 0.538 & 22.61 \\
\hline & 11 & 2.554 & 3.36 \\
\hline \multirow{4}{*}{20} & 1 & 170.608 & -11.64 \\
\hline & 5 & 0.21 & 80.44 \\
\hline & 7 & 0.367 & 33.57 \\
\hline & 11 & 2.639 & 3.34 \\
\hline \multirow{4}{*}{30} & 1 & 169.79 & -11.64 \\
\hline & 5 & 0.334 & 50.59 \\
\hline & 7 & 0.237 & 56.71 \\
\hline & 11 & 1.93 & 4.66 \\
\hline \multirow{4}{*}{40} & 1 & 168.55 & -11.64 \\
\hline & 5 & 0.528 & -34.21 \\
\hline & 7 & 0.21 & -45.01 \\
\hline & 11 & 0.502 & -28.76 \\
\hline \multirow{4}{*}{45} & 1 & 167.376 & -11.64 \\
\hline & 5 & 0.601 & -36.99 \\
\hline & 7 & 0.264 & -64.37 \\
\hline & 11 & 0.419 & 21.73 \\
\hline
\end{tabular}

Table 3. Variation of $\%$ voltage THD with the variation of the pole arc and embrace.

\begin{tabular}{ccc}
\hline Offset $(\mathbf{m m})$ & Embrace & THD (\%) \\
\hline 0 & 0.77 & 1.538 \\
10 & 0.78 & 1.56 \\
20 & 0.81 & 1.713 \\
30 & 0.84 & 1.34 \\
40 & 0.9 & 0.52 \\
45 & 0.99 & 0.48 \\
\hline
\end{tabular}

\section{Conclusion}

In this paper, the optimal pole arc offset for PMSG that is expected to have low THD and high efficiency has been investigated. For the optimal design, pole arc offset value was defined as a variable parameter. While obtaining new designs by varying the pole arcoffset value, utmost care has been exercised to maintain the generator output power almost constant. For this reason, as the value of the pole arc offset is varied, the embrace value is also varied in order to obtain almost constant output power value. Spatial distribution of the air-gap flux density and shape of the phase voltage, corresponding to the various pole arc offset values, have been obtained. Their Fourier analyses have been made. It is well known that as the spatial distribution of the air-gap flux density approaches to a sine wave, the harmonics of the voltage waveforms reduces. As a result, the overall performance of the generators improves. Reduced generator voltage harmonics also results in the reduced circulation currents between the generator and voltage network. As a result of the performed analyses, a pole arc offset value of $40 \mathrm{~mm}$ and a pole embrace value of 0.9 have been identified as highly convenient values. For these values, generator efficiency of $88.24 \%$ and THD value of $0.52 \%$ have been obtained. 


\section{References}

1. Sefa, I. and Altin, N. "Grid interactive photovoltaic inverters-A review" [Güneş Pili Ile Beslenen şebeke Etkileşimli Eviriciler - Genel Bir Bakiş], J. Fac. Eng. Arch. Gazi Univ., 24(3), pp. 409-424 (2009).

2. Dalcali, A., Çelik, E. and Arslan, S. "Design of a microprocessor based electronic governor system for micro and mini hydroelectric power plant" [Mikro ve mini hidroelektrik santralleri için mikrodenetleyici tabanli bir elektronik governor sisteminin tasarimi]", Erciyes Üniversity, Journal of the Institute of Science and Technology, 28(2), pp. 130-135 (2012).

3. Öztürk, N., Dalcali, A., çelik, E. and Sakar, S. "Optimum design of permanent magnet wind generator based on low cogging torque criteria", III. European Conference on Renewable Energy Systems, Antalya (2015).

4. Patil, K. and Mehta, B. "Modeling and simulation of variable speed wind turbine with direct drive permanent magnet synchronous generator", International Conference on Green Computing Communication and Electrical Engineering, Coimbatore, pp. 1-6 (2014).

5. Huang, C., Li, F. and Jin, Z. "Maximum power point tracking strategy for large-scale wind generation systems considering wind turbine dynamics", IEEE Transactions on Industrial Electronics, 62(4), pp. 2530-2539 (2015).

6. Pillai, S.K. and Samuel, P. "Dynamic behaviour of UPF rectifier for PMSG based wind energy conversion system", International conference on embedded systems, Coimbatore, pp. 200-205 (2014).

7. Wang, Y., Meng, J., Zhang, X. and Xu, L. "Control of PMSG-based wind turbines for system inertial response and power oscillation damping", IEEE Transactions on Sustainable Energy, 6(2), pp. 565-574 (2015).

8. Liu, T., Huang S., Deng, Q., Pu, Q. and Huang, K. "Effect of the number of slots per pole on performance of permanent magnet generator direct-driven by wind turbine", International Conference on Electrical Machines and Systems, Beijing, pp. 1-4 (2011).

9. Van, T.L., Nguyen, T.H and Lee, D. "Advanced pitch angle control based on fuzzy logic for variable-speed wind turbine systems", IEEE Transaction on Energy Conversion, 30(2), pp. 578-587, (2015).

10. Polinder, H., van der PijI, F.F.A., de Vilder, G.-J. and Tavner, P. "Comparison of direct-drive and geared generator concepts for wind turbines", International Conference on Electric Machines and Drives, San Antonio, pp. 543-550 (2005).

11. Dursun, E. and Binark, A.K. "Generator which are used in wind turbine (Rüzgar Türbinlerinde Kullanilan Generatöler)", VII. National Clean Energy Symposium, Istanbul, pp. 667- 674 (2008).

12. Kurt, E. and Gör, H. "Electromagnetic design of a new axial flux generator", 6th International Conference on Electronics, Computers and Artificial Intelligence, Romania, pp. 39-42 (2014).

13. Baybpriya, B. and Anita, R. "Modelling, simulation and analysis of doubly fed induction generator for wind turbines", Journal of Electrical Engineering, 60(2), pp. 79-85 (2009).

14. Sekerak, P., Hrabovcova, V., Pyrönen, J., Kalamen, L., Rafajdus, P. and Onufer, M. "Ferrites and different winding types in permanent magnet synchronous motor", Journal of Electrical Engineering, 63(3), pp. 162-170 (2012).

15. Gürdal, O. Designing of Electrical Machines [Elektrik makinlarinin Tasarimi], Bursa Orhangazi University Press, Bursa, Turkey (2015).

16. Tarimer, I., Sakar, S. and Dalcali, A. "Effects of structural design of pole Arc offset in a salient pole generator to obtaining sinusoidal voltages with the least harmonics", Przeglad Elektrotechniczny, 86(11a), pp. 357-362 (2010).

17. Feshki Farahani, H., Khalili, M., Rabiee, A. and Ghazizadeh, M.S. "On the application of plug-in hybrid electric vehicle to compensate network harmonics: A multiobjective approach", Scientia Iranica D, 21(6), pp. 2177-2185 (2014).

18. Wang, K., Shen, J.X., Zhou, F.Z., Qiu, R.H. and Lin, R.G. "Optimal design of magnet pole arc considering utility of third-harmonic back-EMF in highspeed sensorless brushless DC motors", Proceeding of International Conference on Electrical Machines and Systems, Seoul, pp. 680-684 (2007).

19. Boccaletti, C., Felice, P.D., Petrucci, L. and Santini, E. "Parametric analysis of axial flux wind generators focused on total harmonic distortion evaluation", IET Renewable Power Generation, 5(2), pp. 148-159 (2011).

20. Potgieter, J.H.J. and Kamper, M.J. "Torque and voltage quality in design optimization of low-cost nonoverlap single layer winding permanent magnet wind generator", IEEE transactions on Industrial Electronics, 59(5), pp. 2147-2156 (2012).

21. Kim, Y.H., Kwon, S.O., Tao, S. and Hong, J.P. "Initial design using space harmonic analysis methods in permanent magnet synchronous machines", 14 th Biennial IEEE Conference on Electromagnetic Field Computation, Chicago, p. 1 (2010).

22. Wang, D., Wang, X., Yang, Y. and Zhang, R. "Optimization of magnetic pole shifting to reduce cogging torque in solid-rotor permanent-magnet synchronous motors", IEEE Transactions on Magnetics, 46(5), pp. 1228-1234 (2010).

23. Chen, N., Ho, S.L. and Fu, W.N. "Optimization of permanent magnet surface shapes of electric motors for minimization of cogging torque using FEM", IEEE Transactions on Magnetics, 46(6), pp. 24782481 (2010). 
24. Duan, Y. Method for Design and Optimization of Surface Mount Permanent Magnet Machines and Induction Machines, Georgia Institute of Technology (2010).

25. çelik, E. "Graphical interface aided simulation of speed control of permanent magnet synchronous motor with genetic based fuzzy logic controller" [Sürekli miknatisli senkron motor hiz denetiminin genetik tabani bulanik mantik denetleyici ile arayüz destekli simülasyonu], Gazi University Institute of Science (2012).

26. Bayindir, R., Topaloğlu, I. and Ocak, C. "Investigation of the effect of magnet thickness on motor losses of PM BLDC machines using parametric approach method", International Conference on Power Engineering, Energy and Electrical Drives, Malaga, pp. 1-4 (2011).

27. Zheng, P., Liu, Y., Wang, T. and Cheng, S. "Pole optimization of brushless DC motor", IEEE Industry Applications Soc. 39th Annu. Meeting, pp. 1062-1067 (2004).

28. Başman, F. Harmonics in Power Systems and Filter [elektrik enerji sistemlerinde harmonik ve filtreleme], Sakarya University Institute of Science (2006).

29. Öner, Y., Şenol, I., Bekiroğlu, N. and Ayçiçek, E. "Magnetic analysis of fractional slot permanent magnet sychronous machine [Kesirli Oluklu Sürekli Miknatisli Senkron Makinanin Manyetik Analizi], Journal of Engineering and Natural Sciences, Sigma 30(4), pp. 436-446 (2012).

30. Kocatepe, C., Uzunoğlu, M., Yumurtacı, R., Karakas, A. and Arikan, O. Harmonics in Electrical Installations [elektrik tesislerinde harmonikler], Birsen Press, Turkey (2003).
31. Mohan, N., Undeland, T.M. and Robbins, V.P. Power Electronics, John Wiley \& Sons, USA (2003).

\section{Biographies}

Adem Dalcali was born in Turkey in 1986. He received his MSc degree from the Institute of Science and Technology of Gazi University in 2013. He is currently a Research Assistant in Electrical and Electronics Engineering at Karabük University and also is working towards the $\mathrm{PhD}$ degree at the same university. His research interests include CAD of electric machines, numerical analysis of the electromagnetic field in electrical machinery.

Mehmet Akbaba received MSc degree in Electrical Engineering from Istanbul Technical University in 1971, and PhD degree in the same field from Strathclyde University, UK, in 1977. From 1978 to 1983, he was with the Electrical and Electronics Engineering Department, Karadeniz Technical University, Turkey, as a Graduate Assistant, Assistant professor (1978) and Associate Professor (1983),respectively. From 1983 to 2012, he was with the Electrical and Computer Engineering Departments, University of Bahrain as an Assistant Professor (1983), Associate Professor (1986) and full Professor (1995) respectively. Currently, he is with the Computer Engineering Department, Karabuk University, Turkey. He has published over 70 papers in refereed journals and international conferences. His current research interests include modeling and analysis of electromechanical and photovoltaic systems and power electronics. 